\title{
Redução do mal-do-panamá em bananeira-maçã por inoculação de fungo micorrízico arbuscular
}

\author{
Andréa Jaqueira da Silva Borges ${ }^{(1)}$, Aldo Vilar Trindade ${ }^{(2)}$, Aristóteles Pires de Matos $^{(2)}$ \\ e Maria de Fátima da Silva Peixoto(3)
}

\begin{abstract}
(1)Faculdade Maria Milza, Praça Manoel Vitorino, Centro, CEP 44380-000 Cruz das Almas, BA. E-mail: andreajsb@gmail.com (2)Embrapa Mandioca e Fruticultura Tropical, Rua Embrapa, s/no, Caixa Postal 007, CEP 44380-000 Cruz das Almas, BA. E-mail: aldo@cnpmf.embrapa.br, apmatos@cnpmf.embrapa.br (3)Universidade Federal do Recôncavo da Bahia, Campus Universitário, CEP 44380-000 Cruz das Almas, BA. E-mail: fpeixoto@ufba.br
\end{abstract}

\begin{abstract}
Resumo - O objetivo deste trabalho foi avaliar o efeito da densidade de inóculo de fungo micorrízico arbuscular (FMA) na incidência e severidade do Fusarium oxysporum f. sp. cubense (FOC) na bananeira, variedade 'Maçã', em fase inicial de desenvolvimento vegetativo. $\mathrm{O}$ trabalho foi realizado em três etapas, em condições de casa de vegetação, na Embrapa Mandioca e Fruticultura Tropical, Cruz das Almas, BA. Foi realizado um teste de ajuste para determinação das densidades de inóculo do FMA a serem utilizadas. Em seguida, o FMA, Gigaspora margarita, foi inoculado nas mudas de banana e, depois de 60 dias foi inoculado o FOC. G. margarita apresentou eficiência simbiótica no crescimento das mudas de bananeira, variedade Maçã, dependendo da densidade de inóculo. A inoculação prévia com o FMA promoveu redução no índice de infecção causado pelo FOC. A précolonização das plantas de bananeira pelo FMA resultou em efeito de bioproteção, modulado pela taxa de colonização micorrízica e pela concentração de inóculo do FOC no solo.
\end{abstract}

Termos para indexação: Musa sp., Gigaspora margarita, murcha-de-fusário, biocontrole, fusariose.

\section{Reduction of fusarium wilt of "banana-maçã" by inoculation of arbuscular mycorrhizal fungi}

\begin{abstract}
This work aimed to evaluate inoculum density of arbuscular mycorrhizal fungi (AMF) on incidence and effects of Fusarium oxysporum f. sp. cubense (FOC) on Maçã variety of banana (Musa sp.) during its initial growth. An experiment was conducted at Embrapa Mandioca e Fruticultura Tropical, under greenhouse conditions, comprising three stages: a test to adjust levels of inoculum of AMF to be set on the experiment was carried out; therefore, plantlets of banana were inoculated with Gigaspora margarita and, after 60 days, they were inoculated with FOC. G. margarita was efficient for growth of banana plantlets; previous inoculation of AMF reduced disease index caused by FOC, depending on level of inoculum of AMF; previous inoculation of AMF on banana plantlets resulted in bioprotection to FOC, related to level of colonization and level of inoculum of FOC in soil.
\end{abstract}

Index terms: Musa sp., Gigaspora margarita, fusarium wilt, biocontrol.

\section{Introdução}

Entre os principais problemas fitossanitários da bananeira está o mal-do-panamá ou murcha-de-fusário, causado pelo fungo de solo Fusarium oxysporum f. sp. cubense (E.F. Smith) (FOC). Este fungo está distribuído em diferentes condições edafoclimáticas. Infecta diversas variedades de bananeira e causa prejuízos aos bananicultores, por seu grande potencial destrutivo e pela dificuldade de aplicação de medidas de controle.

Por isso, muitos materiais genéticos estão sendo abandonados no Brasil, sendo o principal exemplo, a variedade Maçã, suscetível ao fungo, com áreas de plantio restrita a locais isolados, em solos ainda não cultivados com a banana.

A dificuldade em controlar a fusariose, assim como outras doenças fúngicas, tem estimulado as pesquisas com controle biológico em diferentes culturas (Bodker et al., 1998; Sanfuentes et al., 2002; Cavaglieri et al., 2004; Garmendia et al., 2004; Silva \& Bettiol, 2005)

Os fungos micorrízicos arbusculares (FMA), importantes componentes da microbiota do solo, formam associações simbióticas estáveis com as plantas e podem beneficiá-las de diferentes formas, sendo uma delas a bioproteção contra fungos patogênicos como Fusarium e Phytophthora. Este efeito pode ocorrer por meio dos 
seguintes fatores: melhor nutrição da planta hospedeira; competição por fotossintatos do hospedeiro; competição por infecção/competição local; mudanças morfológicas no sistema radicular; mudanças microbianas na população rizosférica e indução a mecanismos de defesa da planta (Azcón-Aguilar \& Barea, 1996; Smith et al., 1999). Os efeitos protetores da inoculação de FMA podem ser sistêmicos ou localizados (Linderman, 1994; Pozo et al., 2002).

A associação micorrízica ocorre naturalmente em plantios de bananeira (Yano-Melo et al., 1997) e beneficia as plantas sob diferentes condições (Lin \& Fox, 1987; Trindade et al., 2003), nas quais a interação entre FMA e FOC pode ocorrer, representando um potencial a ser explorado no biocontrole do mal-do-panamá. Vários fatores necessitam ser estudados nessa interação para permitir sua manipulação. As mudas micropropagadas no sistema atual podem ir a campo com diversos porcentuais de colonização micorrízica, eventualmente até sem a presença do fungo. O estabelecimento do FMA antes do ataque do patógeno pode induzir aumento da resistência da planta (Mark \& Cassels, 1996; Vigo et al., 2000).

A efetividade do potencial de um agente de controle biológico depende da virulência e do potencial de inóculo dos patógenos no solo (Azcón-Aguilar \& Barea, 1996). Uma alta densidade de inóculo de patógeno na rizosfera pode inviabilizar qualquer forma de biocontrole. Assim, o conhecimento do fator potencial de inóculo de cada microrganismo é importante para a manipulação correta do sistema.

O único controle efetivo para o mal-do-panamá é o plantio de clones e cultivares tolerantes a essa enfermidade (Cordeiro \& Kimati, 1997). Porém, a introdução de fungos micorrízicos pré-selecionados pode contribuir num programa de controle integrado da doença. Caron et al. (1986), trabalhando com tomate, constataram redução da população do Fusarium no solo em que foi introduzido o FMA. A associação do FMA Glomus sp. e F. oxysporum f.sp. gladioli em Gladiolus grandiflorus, em condição de estufa, melhorou o crescimento da planta e a sua resistência em solo infestado pelo patógeno (Gardezi et al., 2001). Em estudo com plantas micropropagadas de banana, variedade Grande Naine (Musa acuminata AAA), em condição de estufa, a inoculação de G. intraradices e Glomus sp. promoveu maior crescimento e reduziu sintomas internos (necrose do rizoma) e externos provocados por F. oxysporum f.sp. cubense (Jaizme-Vega et al., 1997).
O objetivo deste trabalho foi avaliar o efeito da densidade de inóculo de Gigaspora margarita na incidência e severidade de $F$. oxysporum f.sp. cubense na cultura da banana, variedade Maçã, em fase de desenvolvimento vegetativo inicial.

\section{Material e Métodos}

O experimento foi conduzido em condições de estufa de aclimatação e casa de vegetação, de novembro 2001 a maio de 2002, na Embrapa Mandioca e Fruticultura Tropical, Cruz das Almas, BA. Utilizaram-se mudas micropropagadas de bananeira, variedade Maçã, produzidas pela Empresa CAMPO - CPA. A variedade Maçã foi escolhida por sua alta susceptibilidade ao agente causal do mal-do-panamá. As mudas foram obtidas por meio de cultura de meristema, a partir de plantas matrizes do banco ativo de germoplasma da Embrapa Mandioca e Fruticultura Tropical. No início do experimento, as plântulas apresentavam em média $10,3 \mathrm{~cm}$ de altura (medida do colo até o final da última folha), 5 folhas e 10 raízes com o maior comprimento de $8,9 \mathrm{~cm}$.

$\mathrm{O}$ experimento foi realizado em duas etapas. Na primeira, inoculou-se o FMA G. margarita e, na segunda, inoculou-se o FOC nas mesmas plantas. Utilizou-se o delineamento experimental em blocos ao acaso, em esquema fatorial $5 \times 4$, sendo cinco doses de inóculo do FMA (0, 1, 3, 8 e 15 g por planta) e quatro concentrações de inóculo de FOC $\left(0,10^{2}, 10^{3}\right.$, $10^{4}$ macroconídios e microconídios por $\mathrm{mL}$ ), com cinco repetições. As doses de inóculo de FMA foram definidas em ensaio prévio com bananeira.

O isolado de G. margarita foi obtido da coleção do Laboratório de Microbiologia do Solo da Embrapa Mandioca e Fruticultura Tropical, previamente multiplicado na cultura do sorgo (Sorghum bicolor), desenvolvido em mistura de turfa e vermiculita, na proporção 3:1 (v:v), enriquecida com 5\% de esterco bovino, que continha 5 esporos $\mathrm{g}^{-1}$ de inóculo misto, composto também de hifas e raízes colonizadas.

O isolado do FOC foi obtido na coleção do Laboratório de Fitopatologia da Embrapa Mandioca e Fruticultura (TOMBO 095). Na produção do inóculo, o isolado foi repicado, para cultivo, em placas com meio BDA e, posteriormente, colocado em câmara de crescimento por dez dias, a $25^{\circ} \mathrm{C}$. Utilizou-se o corante rosa de bengala para reduzir a taxa de contaminação bacteriana. Depois da purificação do FOC, os conídios foram coletados, utilizando-se $10 \mathrm{~mL}$ de água destilada estéril, esfregando- 
se levemente um pincel sobre as colônias e submetendo-se a suspensão a uma agitação para sua liberação. Determinou-se a concentração da suspensão conidial, em câmara de Newbauer, ajustando-a para ser utilizada na inoculação. A suspensão do inóculo apresentava $1,3 \times 10^{7}$ conídios $\mathrm{mL}^{-1}$ (mistura de macroconídios e microconídios), e foi diluída em água destilada para ficar com $10^{2}, 10^{3}$ e $10^{4}$ conídios $\mathrm{mL}^{-1}$.

A inoculação do FMA foi realizada no momento do transplantio para os vasos, dispondo-se o inóculo em torno das raízes. No tratamento sem inoculação, realizou-se aplicação de um filtrado, obtido pela passagem de suspensão do inóculo em peneira com malha de abertura de $37 \mathrm{~mm}$ (400 mesh), visando a manter a microbiota do inóculo e eliminar os propágulos de FMA. A unidade experimental correspondeu a um vaso, com capacidade de $1 \mathrm{~L}$, contendo uma muda. O substrato utilizado foi composto pela mistura de turfa e vermiculita média (3:1, v:v), enriquecido com $5 \%$ de esterco bovino, previamente fumigado com $394 \mathrm{~mL} \mathrm{~m}^{-3}$ de brometo de metila. Nessa etapa foram utilizadas 25 plantas para cada dose de inóculo.

Aos 20 e 45 dias depois do transplantio, as plantas receberam solução nutritiva que forneceu $10 \mathrm{mg}$ de $\mathrm{N}$ por planta na forma de sulfato de amônio, e $10 \mathrm{~mL}$ de outra solução contendo $6 \mathrm{~g} \mathrm{~L}^{-1}$ de $\mathrm{MgSO}_{4} .7 \mathrm{H}_{2} \mathrm{O}, 3 \mathrm{~g} \mathrm{~L}^{-1}$ de $\mathrm{MnSO}_{4} \mathrm{H}_{2} \mathrm{O}, 3 \mathrm{~g} \mathrm{~L}^{-1}$ de $\mathrm{ZnSO}_{4} .7 \mathrm{H}_{2} \mathrm{O}, 1,5 \mathrm{~g} \mathrm{~L}^{-1}$ de $\mathrm{CuSO}_{4} .5 \mathrm{H}_{2} \mathrm{O}, 0,24 \mathrm{~g} \mathrm{~L}^{-1}$ de $\mathrm{H}_{3} \mathrm{BO}_{3}$ e $0,09 \mathrm{~g} \mathrm{~L}^{-1}$ de $\mathrm{NaMoO}_{4} \cdot 2 \mathrm{H}_{2} \mathrm{O}$. Ao final de 60 dias, 25 plantas foram coletadas para as avaliações de matéria seca da parte aérea e teor de P. No sistema radicular, realizou-se o teste de coloração (Phillips \& Hayman, 1970) e avaliouse o porcentual de colonização micorrízica (Ambler \& Young, 1977).

As plantas restantes foram utilizadas na segunda etapa do experimento, conduzido em blocos casualizados, com cinco repetições, quando o FOC foi inoculado em concentrações de $0,10^{2}, 10^{3} \mathrm{e}$ $10^{4}$ conídios $\mathrm{mL}^{-1}$. Para isto, as mudas foram retiradas do substrato de cultivo da etapa anterior e suas raízes foram imersas, por $20 \mathrm{~min}$, nas diferentes concentrações do FOC. Em seguida, foram transplantadas para vasos com capacidade para $5 \mathrm{~L}$, contendo solo previamente autoclavado, com pH corrigido com adição de $\mathrm{CaCO}_{3}$ (p.a.) e $\mathrm{MgCO}_{3}$, (p.a.) em dosagem equivalente a $1,5 \mathrm{t} \mathrm{ha}^{-1}$, que recebeu $\mathrm{P}$ e $\mathrm{K}$ nas doses de $20 \mathrm{e}$ $80 \mathrm{mg} \mathrm{dm}^{-3}$, respectivamente. As mudas foram levadas para casa de vegetação e, aos 20 e 25 dias, respectivamente, as plantas receberam solução nutritiva contendo $\mathrm{N}$ e micronutrientes, nas mesmas dosagens usadas na etapa anterior. As plantas foram regadas com água destilada de acordo com a necessidade.

Depois de 45 dias de cultivo, procedeu-se à coleta para a avaliação da produção de matéria seca da parte aérea e seu teor de P; o sistema radicular foi separado em raízes e radicelas, medindo-se o comprimento das raízes pelo método direto, com auxílio de régua, e as radicelas pelo método da placa reticulada (Newman, 1966). Uma amostra das radicelas foi utilizada para avaliação do porcentual de colonização micorrízica (Ambler \& Young, 1977).

O índice de infecção (ID) por Fusarium foi calculado de acordo com a fórmula proposta por Cirulli \& Alexander (1966), atribuindo-se notas de 0 a 6, de acordo com escala de avaliação de sintomas proposta por Orjeda (1998):

$\mathrm{ID}=100\left[\Sigma\left(\right.\right.$ nota $\times \mathrm{n}^{\underline{0}}$ de mudas $) /\left(\right.$ nota máxima $\times \mathrm{n}^{\underline{0}} \mathrm{de}$ repetições)].

Os dados obtidos foram submetidos à análise de variância, estimando-se as equações de regressão significativas pelo teste $t(p<0,05)$ a fim de avaliar os efeitos de doses de inóculo de FMA e FOC.

\section{Resultados e Discussão}

A inoculação do fungo micorrízico, em doses crescentes, resultou em porcentagem de colonização com valores acima de $90 \%$, na primeira fase do experimento e antes da inoculação do FOC (Figura 1). O aumento da taxa de colonização iniciou com a menor dose, evidenciando o alto grau de infectividade do fungo $G$. margarita, conforme verificado em trabalho com mamoeiro (Trindade et al., 2000) e

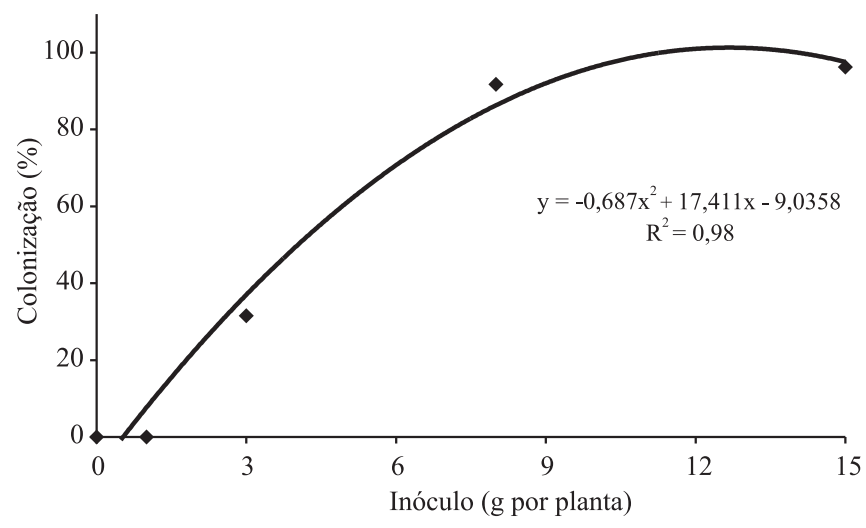

Figura 1. Porcentagem de colonização micorrízica de mudas de banana-maçã sob inoculação de Gigaspora margarita em doses crescentes de inóculo. 
bananeira (Trindade et al., 2003). O uso da maior dose de inóculo do fungo não promoveu incrementos adicionais significativos na taxa de colonização. Esta relação depende de variáveis como o fungo, a planta e o solo.

$\mathrm{O}$ aumento da dose de inóculo também influenciou a produção de matéria seca da parte aérea das mudas de banana-maçã (Figura 2). A resposta foi crescente até a dose de $8 \mathrm{~g}$ por planta. $\mathrm{O}$ coeficiente de correlação (r) entre o acúmulo de matéria seca e porcentagem de colonização foi de 0,89 .

A inoculação do FMA em doses crescentes de inóculo promoveu aumentos significativos nos teores de $\mathrm{P}$ na planta, cujos valores apresentaram elevada correlação $(\mathrm{r}=0,94)$ com a taxa de colonização (Figura 3$)$. Semelhantemente às outras características, o modelo quadrático indicou que o acréscimo de 8 para $15 \mathrm{~g}$ por planta resultou em pequenos incrementos nos teores de P. O sistema radicular da bananeira apresenta radicelas curtas que limitam a exploração de volume maior de solo para a absorção dos nutrientes que apresentam baixa mobilidade. O P não é dos macronutrientes mais absorvidos pela bananeira (Borges \& Silva, 1995), mas a inoculação de FMA na cultura resulta em respostas positivas (Declerck et al., 1994; Trindade et al., 2003).

A inoculação de G. margarita promove respostas significativas também em outras fruteiras, como macieira (Matsubara et al., 2004) e mamoeiro (Trindade et al., 2000).

Não houve efeito da interação FOC x FMA sobre o crescimento de plantas, mas os fatores principais foram significativos. A introdução do FOC, mesmo na menor concentração de inóculo, provocou redução no acúmulo de matéria seca da parte aérea das plantas (Tabela 1).

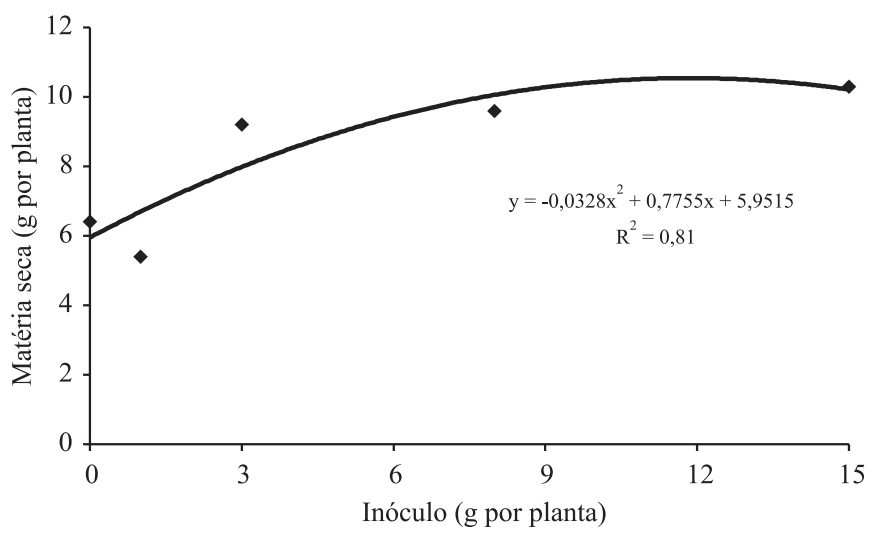

Figura 2. Produção de matéria seca de plantas de bananeiramaçã submetidas a diferentes doses de inóculo de Gigaspora margarita.
A inoculação prévia do FMA resultou em maior acúmulo de matéria seca da parte aérea das mudas de bananamaçã em relação à planta-controle.

A introdução do FOC resultou em índices de infecção de até $70 \%$, aumentando com a dose do patógeno e sendo influenciado pela presença do fungo micorrízico (Figura 4). O FOC mostrou-se infectivo, agressivo e efetivo em provocar danos às plantas. Contribuiu para este resultado a elevada susceptibilidade da variedade Maçã.

As plantas com a dose mais baixa de FOC $\left(10^{2}\right.$ conídios $\left.\mathrm{mL}^{-1}\right)$ desenvolveram índice de doença baixo, independentemente da presença do fungo micorrízico. Nas maiores concentrações de FOC, a micorrização prévia de plântulas de banana-maçã com G. margarita reduziu a infecção pelo patógeno. Este efeito foi significativo em concentrações do FOC de $10^{3}$ conídios $\mathrm{mL}^{-1}$, quando a inoculação do FMA, na dose de $3 \mathrm{~g}$ por planta, reduziu o índice de doença de 43 para $7 \%$. Com a inoculação dessa

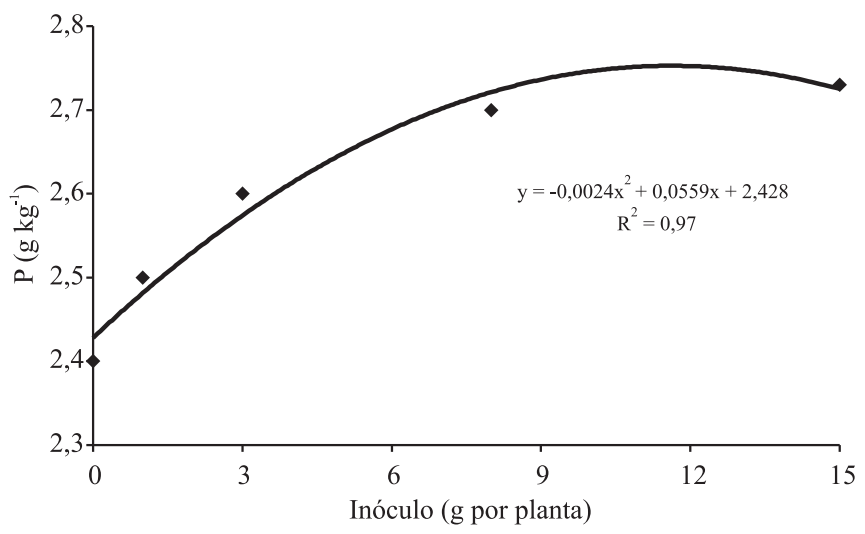

Figura 3. Teores de fósforo na parte aérea de mudas de banana-maçã sob inoculação de Gigaspora margarita em doses crescentes de inóculo.

Tabela 1. Peso de matéria seca de plantas de banana-maçã submetidas a diferentes doses de inóculo de Gigaspora margarita, em diferentes concentrações de Fusarium oxysporum f.sp. cubense (FOC) $)^{(1)}$.

\begin{tabular}{crcccl}
\hline Inóculo & \multicolumn{4}{c}{ FOC (conídios $\left.\mathrm{mL}^{-1}\right)$} & \multirow{2}{*}{ Média } \\
\cline { 2 - 5 } (g por planta) & \multicolumn{1}{c}{0} & 100 & 1.000 & 10.000 & \\
\hline 0 & 8,30 & 7,00 & 6,70 & 5,90 & $6,98 \mathrm{~B}$ \\
1 & 10,21 & 8,84 & 8,53 & 7,38 & $8,74 \mathrm{AB}$ \\
3 & 8,69 & 6,60 & 7,17 & 8,22 & $7,67 \mathrm{BC}$ \\
8 & 10,60 & 9,48 & 8,38 & 8,23 & $9,17 \mathrm{~A}$ \\
15 & 9,96 & 8,27 & 8,10 & 6,39 & $8,18 \mathrm{AB}$ \\
\hline Média & $9,55 \mathrm{a}$ & $8,04 \mathrm{~b}$ & $7,78 \mathrm{~b}$ & $7,22 \mathrm{~b}$ & \\
\hline
\end{tabular}

(1)Médias seguidas pela mesma letra, minúscula na linha e maiúscula na coluna, não diferem entre si pelo teste de Scott-Knott, a 5\% de probabilidade; coeficiente de variação: $16,6 \%$. 
mesma espécie, a incidência de podridão-radicular em plantas de morango, causada por F. oxysporum f.sp. fragariae, diminuiu de 100 para 22\% (Matsubara et al., 2004) e, em aspargo, menos de 50\% das plantas apresentaram sintoma causado por F. oxysporum f.sp. asparagi, em comparação com os $90 \%$ das plantas sem o fungo micorrízico (Matsubara et al., 2001). O uso de inóculo de FMA acima dessa dose não resultou em maiores benefícios quanto ao índice de doença. Portanto, a dose de inóculo de FMA é importante quando a taxa de colonização ainda é baixa.

O controle biológico de doenças de plantas é um dos aspectos importantes da agricultura sustentável. Vários trabalhos têm demonstrado o potencial da utilização de FMA em agir na resistência ou tolerância de diferentes espécies de plantas a patógenos do solo, incluindo diferentes formae specialis de Fusarium (Bodker et al., 1998; Matsubara et al., 2001, 2004; Garmendia et al., 2004), podendo fazer parte de um controle integrado de doenças. Quanto à bananeira, há relatos semelhantes do uso de FMA para o controle de FOC (Jaizme-Vega et al., 1997; Smith et al., 1999; Habeeba et al., 2003). Este efeito protetor dos FMA envolve diversos mecanismos de defesa da planta, tais como a produção de fitoalexinas, quitinases, compostos fenólicos; modificações anatômicas e fisiológicas; liberação de exsudados que estimulam o aparecimento de microrganismos antagônicos; competição por fotossintatos ou sítio de infecção/colonização (Azcón-Aguilar \& Barea, 1996).

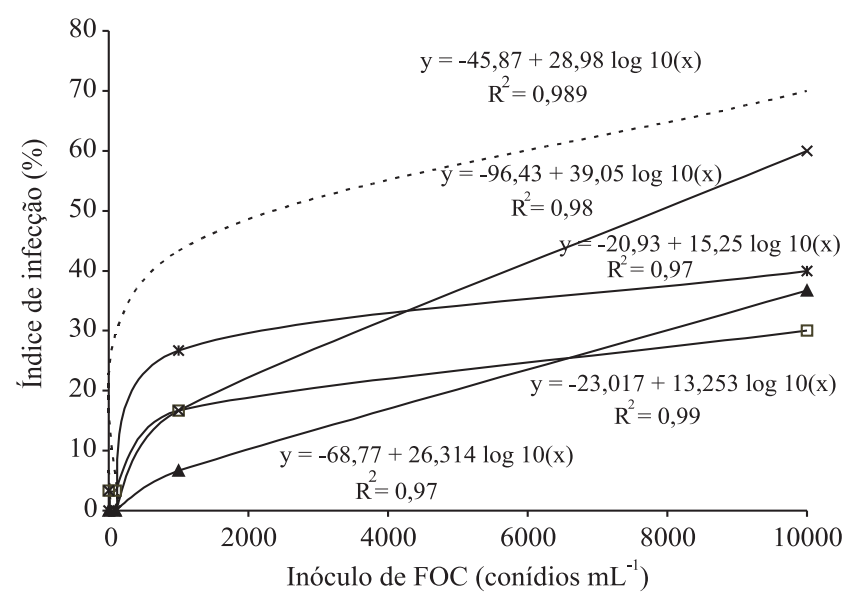

Figura 4. Índice de infecção em plantas de banana-maçã, submetidas a diferentes doses de inóculo de Gigaspora margarita (0: - - -; 1: $\square$; 3: $\mathbf{\Delta}$; 8: × e 15 g por planta: *), em diferentes concentrações de Fusarium oxysporum f.sp. cubense (FOC).
O efeito bioprotetor do FMA em relação ao FOC foi evidenciado pela redução na infecção do patógeno e nos danos causados por ele, quando as mudas de bananeira foram previamente colonizadas com o FMA. Esse efeito pode ter sido causado por um dos mecanismos citados ou a combinação de alguns deles. A relação entre a melhor dose de FMA no controle do patógeno e a maior concentração de $\mathrm{P}$ na planta sugere que o melhor estado nutricional da planta inoculada com o fungo benéfico tenha atuado como um dos mecanismos de bioproteção. Pozo et al. (2002) verificaram que o controle de Phytophtora em tomateiro, utilizando duas espécies de FMA, foi resultado da combinação de mecanismos localizados e sistêmicos.

A introdução do fungo micorrízico antes do FOC promoveu redução no índice de doença. Entretanto, essa redução não foi proporcional à dose do inóculo do FMA, quando a densidade de inóculo do FOC foi a mais alta. Azcón-Aguillar \& Barea (1996) verificaram que uma densidade de inóculo de patógeno alta, na rizosfera, pode inviabilizar qualquer forma de biocontrole. A tecnologia de inoculação de FMA na produção de mudas de bananeira se mostrou benéfica ao crescimento da planta, demonstrando potencial para aplicação no controle integrado do mal-do-panamá.

A colonização por fungos micorrízicos no final do experimento foi influenciada pela inoculação do FOC (Figura 5). Este resultado foi encontrado também por outros autores, mas sem prejuízo para o efeito do FMA no controle

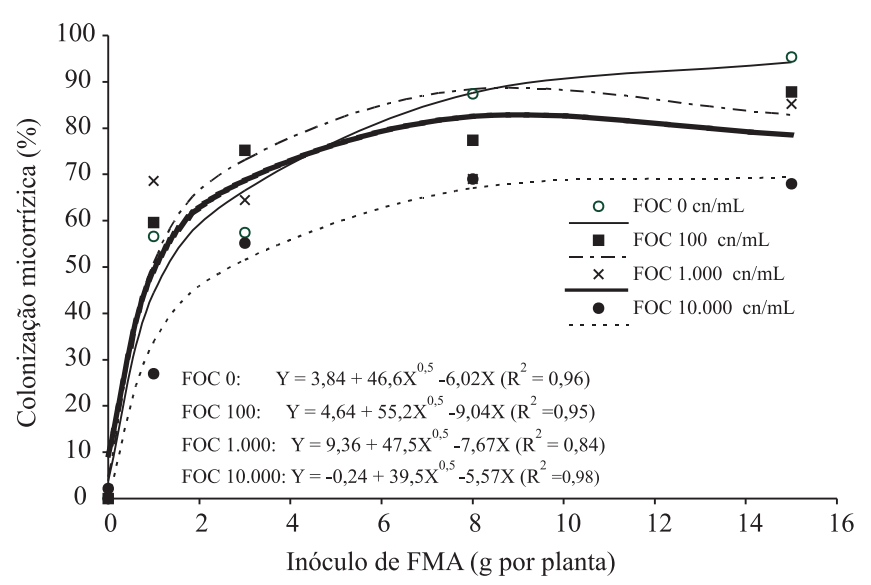

Figura 5. Porcentagem de colonização micorrízica de mudas de banana-maçã em resposta a doses crescentes de inóculo de Gigaspora margarita e posterior inoculação de Fusarium oxysporum f.sp. cubense (FOC). 
do patógeno, seja Fusarium ou Rhizoctonia solani (Abdalla \& Abdel-Fattah, 2000). O uso da maior concentração de FOC causou redução na colonização micorrízica, principalmente na menor dose de inóculo de FMA.

\section{Conclusões}

1. O fungo micorrízico arbuscular Gigaspora margarita apresenta eficiência simbiótica para o crescimento das mudas de bananeira variedade Maçã.

2. A inoculação prévia de G. margarita promove proteção da muda de bananeira 'Maçã' contra o agente causal do mal-do-panamá, Fusarium oxysporum f.sp. cubense.

3. Concentração do inóculo do $F$. oxysporum f.sp. cubense de $10^{4}$ conídios $\mathrm{mL}^{-1}$ reduz a colonização micorrízica.

\section{Referências}

ABDALLA, M.E.; ABDEL-FATTAH, G.M. Influence of the endomycorrhizal fungus Glomus mosseae on the development of peanut pod rot disease in Egypt. Mycorrhiza, v.10, p.29-35, 2000.

AMBLER, J.R.; YOUNG, J.L. Techniques for determining root length infected by vesicular-arbuscular mycorrhizae. Soil Science Society of America Journal, v.41, p.551-556, 1977.

AZCÓN-AGUILAR, C.; BAREA, J.M. Arbuscular mycorrhizas and biological control of soil-borne plant pathogens: an overview of the mechanisms involved. Mycorrhiza, v.6, p.457-464, 1996.

BØDKER, L.; KJØLLER, R.; ROSENDAHL, S. Effect of phosphate and the arbuscular mycorrhizal fungus Glomus intraradices on disease severity of root rot of peas (Pisum sativum) caused by Aphanomyces euteiches. Mycorrhiza, v.8, p.169-174, 1998.

BORGES, A.L.; SILVA, S. de O. Extração de macronutrientes por cultivares de banana. Revista Brasileira de Fruticultura, v.17, p.57-66, 1995.

CARON, M.; FORTIN, J.A.; RICHARD, C. Effect of Glomus intraradices on the infection by Fusarium oxysporum f. sp. radicislycopersici on tomatoes over a twelve-week period. Canadian Journal of Botany, v.64, p.552-556, 1986.

CAVAGLIERI, L.R.; PASSONE, A.; ETCHEVERRY, M.G. Correlation between screening procedures to select root endophytes for biological control of Fusarium verticillioides in Zea mays L. Biological Control, v.31, p.259-267, 2004.

CIRULLI, M.; ALEXANDER, L.J. A comparison of pathogenic isolates of Fusarium oxysporum f. licopersici and different sources of resistance in tomato. Phytopathology, v.56, p.1301-1304, 1966.

CORDEIRO, Z.J.M.; KIMATI, H. Doenças da bananeira (Musa sp.). In: KIMATI, H.; AMORIM, L.; BERGAMIN FILHO, A.; CAMARGO, L.E.A.; REZENDE, J.A.M. (Ed.). Manual de fitopatologia: doenças das plantas cultivadas. 3.ed. São Paulo: Agronômica Ceres, 1997. v.2, p.112-136.

DECLERCK, S.; DEVOS, B.; DELVAUX, B.; PLENCHETTE, C. Growth response of micropropagated banana plants to VAM inoculation. Fruits, v.49, p.103-109, 1994.

GARDEZI, A.K.; CETINA-ALCALÁ, V.M.; FERRERACERRATO, R.; VELÁSQUEZ-MENDOZA, J.; PÉREZMERCADO, C.A.; LARQUÉ-SAAVEDRA, M. Hongos micorrizicos arbusculares como componente de control biologico de la pudricion causada por Fusarium sp. en gladiola. Terra, v.19, p.259-264, 2001.

GARMENDIA, I.; GOECOICHEA, N.; AGUIRREOLEA, J. Effectiveness of three Glomus species in protecting pepper (Capsicum annuum L.) against verticillium wilt. Biological Control, v.31, p.296-305, 2004.

HABEEBA, T.; RAVICHANDRA, N.G.; KRISHNAPPA, K.; REDDY, B.M.R. Interaction of Glumus fasciculatum in the management of burrowing nematode, Radopholus similis and wilt fungus, Fusarium oxysporum f.sp. cubense on banana. In: NATIONAL SYMPOSIUM ON BIODIVERSITY AND MANAGEMENT OF NEMATODES IN CROPPING SYSTEMS FOR SUSTAINABLE AGRICULTURE, 2002, Jaipur. Proceedings. New Delhi: Iari, 2003. p.244-250.

JAIZME-VEGA, M.C.; SOSA HERNÁNDEZ, B.; HERNÁNDEZ HERNÁNDEZ, J.M. Interaction of arbuscular mycorrhizal fungi and the soil pathogen Fusarium oxysporum f.sp. cubense on the first stages of micropropagated Grande Naine banana. Acta Horticulturae, v.490, p.285-295, 1997.

LIN, M.L.; FOX, R.L. External and internal P requirements of mycorrhizal and non-mycorrhizal banana plants. Journal of Plant Nutrition, v.10, p.1341-1348, 1987.

LINDERMAN, R.G. Role of VAM fungi in biocontrol. In: PFLEGER, F.L.; LINDERMAN, R.G. Mycorrhizae and plant health. St. Paul: APS Press, 1994. p.1-26.

MARK, G.L.; CASSELLS, A.C. Genotype-dependence in the interaction between Glomus fistulosum, Phytophthora fragariae and the wild strawberry (Fragaria vesca). Plant and Soil v.185, p.233239, 1996.

MATSUBARA, Y.; HIRANO, I.; SASSA, D.; KOSHIKAWA, K. Increased tolerance to fusarium wilt in mycorrhizal strawberry plants raised by capillary watering methods. Environment Control in Biology, v.42, p.185-191, 2004.

MATSUBARA, Y.; OHBA, N.; FUKUI, H. Effect of arbuscular mycorrhizal fungus infection on the incidence of fusarium root rot in Asparagus seedlings. Journal of the Japanese Society for Horticultural Science, v.70, p.202-206, 2001.

NEWMAN, E.I. A method of estimating total length of root in a sample. Journal of Applied Ecology, v.3, p.139-145, 1966.

ORJEDA, G. Evaluation of Musa germplasm for resistance to Sigatoka diseases and Fusarium wilt. Montpellier: Inibap, 1998. 63p. (Inibap technical guidelines, 3).

PHILLIPS, J.M.; HAYMAN, D.S. Improved procedures for clearing roots and staining parasitic and vesicular-arbuscular mycorrhizal fungi for rapid assessment of infection. Transactions of the British Mycological Society, v.55, p.158-161, 1970. 
POZO, M.J.; CORDIER, C.; DUMAS-GAUDOT, E.; GIANINAZZI, S.; BAREA, J.M.; AZCÓN-AGUILAR, C. Localized versus systemic effect of arbuscular mycorrhizal fungi on defence responses to Phytophthora infection in tomato plants. Journal of Experimental Botany, v.368, p.525-534, 2002.

SANFUENTES, E.A.; ALFENAS, A.C.; MAFFIA, L.A.; SILVEIRA, S.F.; PENCHEL, R.; SARTORIO, R.C. Supressão da atividade saprofítica de Rhizoctonia spp. em solos de jardim clonal de Eucalyptus. Fitopatologia Brasileira, v.27, p.461-467, 2002.

SILVA, J.C. da; BETTIOL, W. Potential of non-pathogenic Fusarium oxysporum isolates for control of Fusarium wilt of tomato. Fitopatologia Brasileira, v.30, p.409-412, 2005.

SMITH, L.J.; SMITH, M.K.; HAMILL, S.D.; HUNTER, M.N.; PEGG, K.G.; GALEA, V.J. Towards improving resistance of micropropagated bananas to Fusarium wilt using bacteria and bacteria and mycorrhizae. I. Bioassay development. In: MOLINA, A.B.; NIK MASDEK, N.H.; LIEW, K.W. Banana fusarium wilt management: towards sustainable cultivation. Malásia: Inibap, 1999. p.224-233.

TRINDADE, A.V.; LINS, G.M. de L.; MAIA, I.C.S. Substratos e fungo micorrízico arbuscular em mudas micropropagadas de bananeira na fase de aclimatação. Revista Brasileira de Fruticultura, v.25, p.137-142, 2003.

TRINDADE, A.V.; SIQUEIRA, J.O.; ALMEIDA, F.P. Eficiência simbiótica de fungos micorrízicos arbusculares em solo não fumigado, para mamoeiro. Revista Brasileira de Ciência do Solo, v.24, p.506$512,2000$.

VIGO, C.; NORMAN, J.R.; HOOKER, J.E. Biocontrol of the pathogen Phytophthora parasitica by arbuscular mycorrhizal fungi is a consequence of effects on infection loci. Plant Pathology, v.49, p.509-514, 2000.

YANO-MELO, A.M.; MAIA, L.C.; MORGADO, L.B. Fungos micorrízicos arbusculares em bananeiras cultivadas no Vale do Submédio São Francisco. Acta Botanica Brasilica, v.11, p.115121, 1997.

Recebido em 20 de junho de 2005 e aprovado em 16 de outubro de 2006 